\title{
Downregulation of Frizzled-7 induces the apoptosis of hepatocellular carcinoma cells through inhibition of NF-кB
}

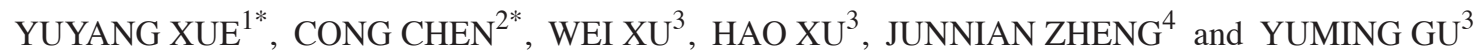 \\ ${ }^{1}$ Department of Interventional Radiology, The No. 1 Hospital of Xuzhou, \\ Xuzhou, Jiangsu 221002; ${ }^{2}$ State Key Laboratory of Oncogenes and Related Genes, \\ Shanghai Cancer Institute, Renji Hospital, Shanghai Jiaotong University School of Medicine, \\ Shanghai 200025; ${ }^{3}$ Department of Interventional Radiology, Affiliated Hospital of Xuzhou Medical College; \\ ${ }^{4}$ Jiangsu Key Laboratory of Biological Cancer Therapy, Xuzhou Medical College, Xuzhou, Jiangsu 221002, P.R. China
}

Received December 16, 2015; Accepted May 16, 2017

DOI: $10.3892 / \mathrm{ol} .2018 .8292$

\begin{abstract}
The aim of the present study was to investigate the functional role of Frizzled-7 (FZD7) in the apoptosis of hepatoma cells. HepG2 and Huh-7 hepatocellular carcinoma (HCC) cell lines with FZD7 expression were selected for use in the present study. The small hairpin RNA (shRNA) eukaryotic expression vector specific to FZD7 was constructed using gene recombination, and was then transfected into HepG2 and Huh-7 hepatoma cell lines using Lipofectamine 2000 to assess whether the downregulation of FZD7 could affect the proliferative ability of these cells. The results demonstrated that the downregulation of FZD7 expression significantly inhibited the proliferative ability of both cell types through the induction of cell apoptosis, as evidenced using Cell Counting kit- 8 assays and flow cytometry. Furthermore, the western blotting results demonstrated that silencing of FZD7 increased the activities of caspase- 3 and caspase- 9 . These increases were also associated with the downregulation of the inhibitor of the apoptosis protein family. Additionally, it was revealed that silencing of FZD7 expression caused the downregulation of apoptosis regulator Bcl-2 and Bcl-XL in HepG2, and Huh-7 cells, as determined through western blot analysis and reverse transcription-quantitative polymerase chain reaction. In the following work, ELISA and western blot analysis revealed that the knockdown of FZD7 inhibited the expression and activities of nuclear factor $-\kappa \mathrm{B}(\mathrm{NF}-\kappa \mathrm{B}) \mathrm{p} 65$. Furthermore, it was demonstrated that the expression levels of phosphylated-Smad2/3 were markedly upregulated in
\end{abstract}

Correspondence to: Professor Yuming Gu, Department of Interventional Radiology, Affiliated Hospital of Xuzhou Medical College, 99 West Huaihai Road, Xuzhou, Jiangsu 221002, P.R. China E-mail: guyuming_2006@163.com

${ }^{*}$ Contributed equally

Key words: frizzled-7, hepatocellular carcinoma, apoptosis, nuclear factor- $\kappa \mathrm{B}$, transforming growth factor- $\beta / \mathrm{Smad}$
sh-FZD7-transfected HepG2 and Huh-7 cells. Then, shRNA eukaryotic expression vector specific to transforming growth factor (TGF)- $\beta$ receptor II was transfected into both cell lines to investigate the association between the TGF- $\beta /$ Smad signaling pathway and NF- $\mathrm{B}$ p 65 . Notably, when the TGF- $\beta / \mathrm{Smad}$ signaling pathway was inhibited, no significant differences in the cell apoptosis rate and $\mathrm{NF}-\kappa \mathrm{B}$ expression levels were identified in HCC cells. Overall, the results of the present study suggest that the shRNA-mediated knockdown of FZD7 induces apoptosis of hepatoma cell lines through the inhibition of $\mathrm{NF}-\kappa \mathrm{B}$. In addition, the TGF- $\beta /$ Smad signaling pathway appeared to partially participate in the underlying molecular mechanism of FZD7 in HCC.

\section{Introduction}

The Wnt/ $\beta$-catenin signaling pathway is one of the most significant signaling pathways involved in the regulation of cell proliferation, differentiation, migration, apoptosis and survival $(1,2)$. It has been demonstrated to be dysregulated in human hepatocellular carcinoma (HCC) (3), gastric cancer (4), breast cancer (5) and colon cancer (6,7). Frizzled-7 (FZD7) is an important receptor for Wnt signaling, which binds to Wnt proteins and subsequently activates either canonical or noncanonical Wnt signaling pathways (8). When Wnt ligands bind to the Frizzled receptor, glycogen synthase kinase $3 \beta$ (GSK3 $\beta$ ) is released from the adenomatous polyposis coli/Axin/GSK3 $\beta$ complex and thus its activity is inhibited $(9,10)$. Subsequently $\beta$-catenin is released, accumulated in the cytoplasm and translocated to the nucleus where it can regulate the transcription of target genes associated with cell proliferation, and survival through an interaction with $\mathrm{T}$ cell factor $(\mathrm{TCF}) / \mathrm{lymphoid}$ enhancer factor (LEF) family transcription factors and Legless family docking proteins $(9,10)$. Some of the essential downstream proteins and genes that are activated following the binding of $\beta$-catenin to transcriptional factors of the canonical pathway include c-MYC, Cyclin D1, Survivin, Axin2, and matrix metalloproteinases (11).

In our previous investigations, it was revealed that short hairpin (sh)RNA-mediated knockdown of FZD7 inhibits invasion, metastasis and epithelial-mesenchymal transition 
of HepG2, and Huh-7 cell lines (12). In addition, previous studies have demonstrated that the secreted Frizzled-related protein 4, which functions as antagonists of Wnt signaling by inhibiting Wnt-FZD interactions, elicited apoptosis in ovarian (13), gastric (14), colorectal (15) and mammary (16) tumors. Furthermore, Nambotin et al (17) reported that in vitro and in vivo, the pharmacological inhibition of FZD7 induces apoptosis of HCC cell lines through the modulation of protein kinase $\mathrm{C} \delta(\mathrm{PKC} \delta)$ and $\beta$-catenin; however, the other molecular mechanisms involved remain unclear.

The present study aimed to investigate the role of FZD7 on the proliferation and apoptosis of HepG2, and Huh-7 HCC cell lines. Furthermore, the expression levels of several important genes that are associated with apoptosis signaling were assayed in order to determine the underlying molecular mechanism of FZD7 in HCC and identify novel therapeutic targets for $\mathrm{HCC}$ treatment.

\section{Materials and methods}

Cell culture. Human hepatoma cell lines (HepG2 and Huh-7) were obtained from the Type Culture Collection of the Chinese Academy of Sciences (Shanghai, China). Both cells were grown in Dulbecco's modified Eagle's medium (DMEM; Gibco; Thermo Fisher Scientific, Inc., Waltham, MA, USA) supplemented with $10 \%$ heat-inactivated fetal bovine serum (FBS; Gibco; Thermo Fisher Scientific, Inc.), $100 \mathrm{U} / \mathrm{ml}$ penicillin and $100 \mu \mathrm{g} / \mathrm{ml}$ streptomycin. Both cell lines were cultured at $37^{\circ} \mathrm{C}$ in a humidified atmosphere with $5 \% \mathrm{CO}_{2}$.

RNA interference and transfection. ShRNA sequences for FZD7 and transforming growth factor- $\beta$ receptor II (TGF- $\beta$ RII) were inserted into the $B b s \mathrm{I}$ and $\mathrm{BamHI}$ sites of the pGPU6/GFP/Neo vector (Shanghai GenePharma Co. Ltd., Shanghai, China). The resulting oligonucleotides sequences were termed sh-FZD7 and sh-TGF- $\beta$ RII. ShRNA with a scrambled nonspecific sequence was used as a negative control (sh-NC). When the cells were grown to $80 \%$ confluence, sh-FZD7, sh-TGF- $\beta$ RII, and sh-NC plasmids were transfected into cells using Lipofectamine 2000 reagent (Invitrogen; Thermo Fisher Scientific, Inc.) according to the manufacturer's protocol. Then the medium was changed $4-6 \mathrm{~h}$ after transfection to avoid the problem of toxicity. Following $48 \mathrm{~h}$ transfection, the cells were collected for use in subsequent experiments.

Western blot analysis. Each group of cells was harvested and lysed by a protein lysis buffer (Beyotime Institute of Biotechnology, Nantong, China), and the concentrations of the protein were measured utilizing a BCA assay (Beyotime Institute of Biotechnology, Nantong, China). All protein samples were denatured by mixing with loading buffer (Beyotime Institute of Biotechnology). After boiling for $5 \mathrm{~min}$, equal amounts of protein $(30 \mu \mathrm{g} /$ lane $)$ were subjected to $8-12 \%$ SDS-PAGE and transferred onto nitrocellulose membranes (GE Healthcare, Chicago, IL, USA) through a wet or semi-dry transfer. Then the membranes were blocked with $5 \%$ nonfat milk diluted in Tris-buffered saline with Tween 20 (TBST) for $2 \mathrm{~h}$ at room temperature (RT). Next, the blots were incubated overnight at $4^{\circ} \mathrm{C}$ with primary rabbit anti-human antibodies against FZD7 (cat. no. BS2774), pro-caspase-3 (cat. no. BS1518), caspase-9 (cat. no. AP0186), nuclear factor (NF)- $\kappa$ B p65 (cat. no. BS1252), Smad2/3 (cat. no. BS1838), phosphorylated (P)-Smad2/3 (cat. no. AP0326) and $\beta$-actin (cat. no. AP0731) purchased from Bioworld Technology, Inc. (St. Louis Park, MN, USA); mouse/rabbit anti-human $\beta$-catenin (cat. no. sc-59737), apoptosis regulator Bcl-2 (Bcl-2; cat. no. sc-70411), cellular tumor antigen p53 (p53; cat. no. sc-393031), X-linked inhibitor of apoptosis (XIAP; cat. no. sc-55550), cellular inhibitor of apoptosis (cIAP)-1 (cat. no. sc-271419) and cIAP-2 (cat. no. sc-517317) purchased from Santa Cruz Biotechnology, Inc. (Dallas, TX, USA); and rabbit anti-human Bcl-2 extra large protein (Bcl-XL; cat. no. 2764), BCL2 associated $X$ apoptosis regulator (Bax; cat. no. 5023) and cleaved caspase-3 (cat. no. 9661) purchased from Cell Signaling Technology, Inc. (Danvers, MA, USA). The $\beta$-actin was diluted 1:5,000 in 5\% skimmed milk, and other primary antibodies were diluted 1:1,000 in the same liquid. This was followed by incubation with the appropriate monoclonal goat anti-mouse (cat. no. RK-610-131-003) or anti-rabbit (cat. no. RK-611-130-002) immunofluorescence-conjugated secondary antibodies (dilution, 1:10,000; LI-COR Biosciences, Lincoln, NE, USA) for $1 \mathrm{~h}$ at room temperature. After each incubation, membranes were washed three times with TBST for $10 \mathrm{~min}$ at room temperature. Finally, the bands of specific proteins on the nitrocellulose membranes were visualized using an Odyssey infrared imaging system (Odyssey; LI-COR Biosciences).

Cell proliferation assay. The $100 \mu \mathrm{l}$ cell suspension of HepG2 or Huh-7 cells ( $3 \times 10^{3}$ cells/well) was seeded in 96-well culture plates (Corning Incorporated, NY, USA). After culturing for $24,48,72$ and $96 \mathrm{~h}$ at $37^{\circ} \mathrm{C}$ in a humidified incubator with $5 \% \mathrm{CO}_{2}$, the supernatant was removed and $100 \mu \mathrm{l}$ serum-free DMEM and $10 \mu \mathrm{l}$ Cell counting kit-8 (CCK-8; Dojindo Molecular Technologies, Inc., Kumamoto, Japan) solution were added into six wells of each sample, followed by incubation at $37^{\circ} \mathrm{C}$ in $5 \% \mathrm{CO}_{2}$ for $2 \mathrm{~h}$. The absorbance was measured at a wavelength of $450 \mathrm{~nm}$ using an ELX-800 spectrometer reader (Omega Bio-Tek, Inc., Norcross, GA, USA). Then growth curves were calculated and plotted. The experiment was performed in triplicate.

Flow cytometric analysis of apoptosis. Hepatoma cells were trypsinized, washed twice with cold phosphate buffered saline (PBS) and apoptosis rates were determined using flow cytometric analysis with annexin V-fluorescein isothiocyanate (FITC)/propidium iodide (PI) staining (BD Biosciences, Franklin Lakes, NJ, USA) according to the manufacturer's protocol. A total of $500 \mu \mathrm{l}$ binding buffer, $5 \mu \mathrm{l}$ Annexin V-FITC and $5 \mu \mathrm{l}$ PI was added to the cells. Cells were then incubated in the dark at RT for $10 \mathrm{~min}$. Subsequently, the cell apoptosis rate was analyzed using flow cytometry (FACScan, BD Biosciences). All experiments were repeated $\geq 3$ times.

Reverse transcription-quantitative polymerase chain reaction (RT-qPCR). Total RNA from the hepatoma cells was extracted using TRNzol reagent (TianGen Biotech Co., Ltd., Beijing, China), and the reverse transcribed into cDNA using the reverse transcription kit (FastKing gDNA Dispelling 


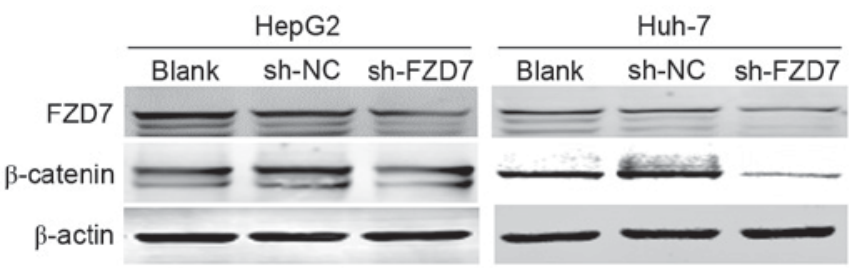

Figure 1. Knockdown of FZD7 inhibits Wnt/ $\beta$-catenin signaling in HepG2 and Huh-7 cells. $\beta$-actin was probed as a loading control. The objective band of FZD7 is clear, but there are some multiple bands. $\beta$-catenin of HepG2 includes wild type and mutant type. FZD7, Frizzled-7; sh, short hairpin; NC, negative control.

RT SuperMix; cat. no. KR118; TianGen Biotech Co., Ltd.) according to the manufacturer's protocol $\left(42^{\circ} \mathrm{C}\right.$ for $15 \mathrm{~min}$, and $95^{\circ} \mathrm{C}$ for $3 \mathrm{~min}$ ). qPCR was performed using a two-step program with a 7500 real-time PCR system (Applied Biosystems; Thermo Fisher Scientific, Inc.) as follows: $95^{\circ} \mathrm{C}$ for $15 \mathrm{~min}$; 40 cycles consisting of $95^{\circ} \mathrm{C}$ for $10 \mathrm{sec}$ and $64^{\circ} \mathrm{C}$ for $32 \mathrm{sec}$. GAPDH was used as the internal control. The change of each target gene relative mRNA lever was measured using the $2^{-\Delta \Delta \mathrm{Cq}}$ method (18). All the detection kits were purchased from Tiangen Biotech Co., Ltd. (Beijing, China). The primers were obtained from Shanghai Genebase Gene-Tech Co., Ltd. (Shanghai, China), and sequences were as follows: GAPDH forward, 5'-AGAAGGCTGGGGCTCATTTG-3' and reverse, 5'-AGGGGCCATCCACAGTCTTC-3'; Bax forward, 5'-ATG GGCTGGACATTGGACTT-3' and reverse, 5'-ATGGTG AGTGAGGCGGTGA-3'; Bcl-2 forward, 5'-TCCATGTCT TTGGACAACCA-3' and reverse, 5'-CTCCACCAGTGTTCC CATCT-3'; Bcl-XL forward, 5'-GGCTGCTTGGGATAA AGATG-3' and reverse, 5'-GAAGGGACTAGGGTGGTG CT-3'; XIAP forward, 5'-CCTCACAAAGTGCTGGGATT-3' and reverse, 5'-CTCGGAAACTGCTGGGATTA-3'; cIAP-1 forward, 5'-CCTGATGCTGGATAACTGGAA-3' and reverse, 5'-GGCTGGAGTAAGAACCACTGA-3'; cIAP-2 forward, 5'-CCTGATGCTGGATAACTGGAA-3' and reverse, 5'-TTG AATAAGAGCCACGGAAA-3'.

ELISA. Nuclear protein was extracted using a Nuclear and Cytoplasmic Protein Extraction kit (Beyotime Institute of Biotechnology). The level of phosphorylated NF- $\kappa \mathrm{B}$ p65 (Ser536) of the nuclear protein was quantified using the Sandwich ELISA kit according to the manufacturer's protocol (Cell Signaling Technology, Inc.). The absorbance value (OD value) of each well was measured at a wavelength of $450 \mathrm{~nm}$ using an ELX-800 spectrometer reader (Omega Bio-Tek, Inc.). The sample concentration was calculated according to the OD value and standard curve.

Statistical analysis. Experimental data are presented as the mean \pm standard deviation and were analyzed using SPSS software (version 16.0; SPSS, Inc., Chicago,IL, USA). One-way analysis of variance followed by Least significant difference test and Dunnett's T3 was used to assess significant differences among groups. The bar and line charts were produced using GraphPad Prism software (version 5.0; GraphPad Software, Inc., La Jolla, CA, USA). $\mathrm{P}<0.05$ was considered to indicate a statistically significant difference (two-tailed).

\section{Results}

Downregulation of FZD7 expression inhibits the Wnt/ $\beta$-catenin signaling pathway in HepG2 and Huh-7 cells. Two hepatoma cell lines with high expression levels of FZD7 were selected, HepG2 and Huh-7. The vectors that expressed shRNA against FZD7 were transfected into HepG2 and Huh-7 cells. Western blotting results demonstrated that the FZD7 and $\beta$-catenin protein expression levels were markedly decreased in the sh-FZD7 group compared with the sh-NC-transfected and blank groups in both cell lines (Fig. 1). These results suggest that the Wnt/ $\beta$-catenin signaling pathway was inhibited in sh-FZD7-transfected HepG2 and Huh-7 cells. The objective band of FZD7 is clear, but there are some mixed bands. The $\beta$-catenin of HepG2 includes wild type and mutant type.

Growth inhibition of HepG2 and Huh-7 cells through silencing of FZD7 expression. The effects of FZD7 silencing on the proliferation of hepatoma cells were determined using CCK-8 assays. As presented in Fig. 2A, the proliferative ability of sh-FZD7-transfected cells was significantly suppressed following 48, 72 and $96 \mathrm{~h}$ incubation, when compared with the sh-NC-transfected and blank groups (all $\mathrm{P}<0.05$ ). However, no significant differences were identified between the blank and sh-NC groups ( $\mathrm{P}>0.1$; Fig. 2A).

FZD7 knockdown promotes the apoptosis of HepG2 and Huh-7 cells. Flow cytometric analysis demonstrated that the apoptotic rate of the HepG2 cells in the sh-FZD7 group $(43.90 \pm 2.61 \%)$ was significantly increased compared with that of the blank $(14.12 \pm 1.39 \%)$ and sh-NC $(16.82 \pm 1.26 \%)$ groups (both $\mathrm{P}<0.01)$. Similarly, in Huh-7 cells, the apoptotic rate in the sh-FZD7 group $(45.80 \pm 3.90 \%)$ were markedly higher compared with that of the blank $(8.54 \pm 1.12 \%)$ and sh-NC $(7.92 \pm 1.06 \%)$ groups (both $\mathrm{P}<0.01)$. These results indicate that FZD7 knockdown induces the apoptosis of the HepG2 and Huh-7 cells (Fig. 2B).

Effects of FZD7 knockdown on the expression of apoptosis-associated genes in HepG2 and Huh-7 cells. In order to determine the possible mechanism underlying FZD7 knockdown-induced cell apoptosis, the expression levels of capase- 3 and caspase-9 were detected in HepG2 and Huh-7 cells using western blot analysis. The results demonstrated that silencing of FZD7 markedly upregulated the levels of the cleaved caspase- 3 and cleaved caspase- 9 protein $(35 \mathrm{kDa})$, but the pro-caspase- 3 and pro-caspase-9 (48 kDa) expression levels remained unchanged or markedly downregulated in both cell lines (Fig. 3A).

The IAP family proteins are direct inhibitors of activated caspases, which lead to caspase inactivation in eukaryotic cells. Accordingly, the involvement of the IAP family in HepG2 and Huh-7 cells was further analyzed at the protein, and mRNA levels. The results indicated that the protein levels of XIAP, cIAP-1 and cIAP-2 were markedly inhibited by different degrees in sh-FZD7-transfected HepG2 cells when compared with the sh-NC and blank groups (Fig. 3B). Nevertheless, the cIAP-1 and cIAP-2 mRNA expression levels were significantly suppressed in sh-FZD7-transfected Huh-7 cells with no significant differences identified in the level of XIAP (Fig. 3B). 

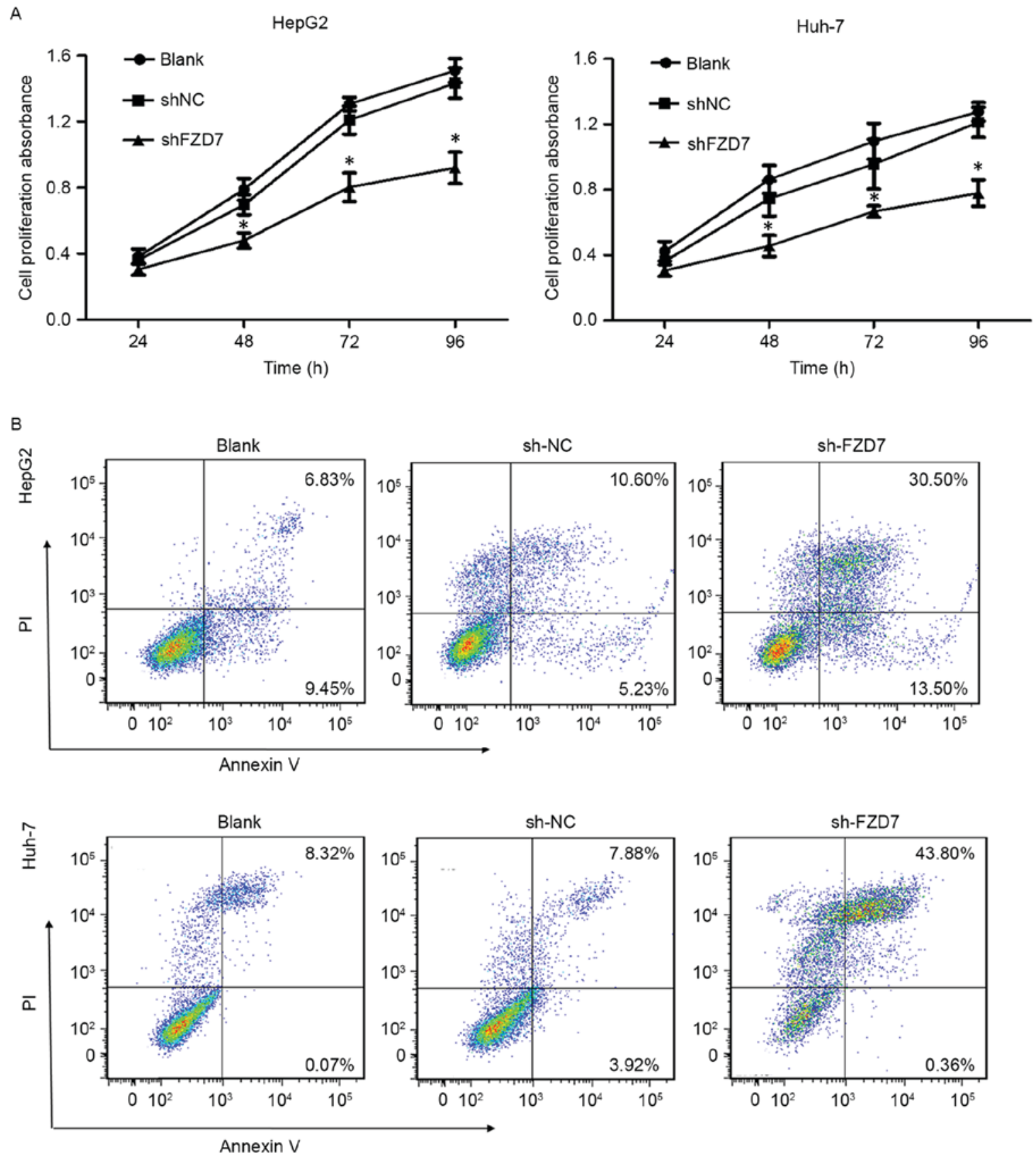

Figure 2. Effects of knockdown of FZD7 on the proliferation and apoptosis in HepG2, and Huh-7 cells. (A) Inhibition of cell proliferation in FZD7 shRNA-transfected HepG2 and Huh-7 cells. Data are presented as the mean \pm standard deviation of three independent experiments $\left(\mathrm{n}=3\right.$; ${ }^{*} \mathrm{P}<0.05$, compared with blank and sh-NC). (B) Downregulation of FZD7 induced apoptosis in HepG2 and Huh-7 cells. FITC, fluorescein isothiocyanate; PI, propidium iodide; FZD7, Frizzled-7; sh, short hairpin; NC, negative control.

Bcl-2 family members also serve an important role in the process of apoptosis. The apoptotic cascades involved in the sh-FZD7-transfected HepG2 and Huh-7 cells were investigated by silencing FZD7, and comparing the levels of the Bcl-2 family members. RT-qPCR and western blot analysis demonstrated that no significant differences occurred in the transcriptional, and translational levels of pro-apoptotic Bax in sh-FZD7-transfected HepG2 and Huh-7 cells compared with the two control groups (Fig. 3C). However, the protein expression levels of anti-apoptotic Bcl-2 and Bcl-XL were markedly downregulated, with corresponding significant differences observed in the mRNA expression in response to the sh-FZD7 transfection in both cell lines (Fig. 3C).
Modulation of IAP and Bcl-2 families by inhibition of NF- $\kappa B$ P65 nuclear translocation in sh-FZD7-transfected HepG2, and Huh-7 cells. NF- $\mathrm{KB}$ is an essential nuclear receptor responsible for cellular proliferation and apoptosis, which participates in the transcription of a variety of functional genes, such as IAP and Bcl-2 family members. Therefore, the expression and activities of NF- $\mathrm{kB}$ p65 in HepG2, and Huh-7 cells were further examined. Total, nuclear and plasma protein samples were extracted, and used for the detection of NF- $\kappa B$ p 65 . The western blotting results demonstrated that nuclear protein expression was markedly decreased following sh-FZD7 transfection, but no marked differences observed in plasma protein expression on the basis of reduced total protein (Fig. 4A). 
A

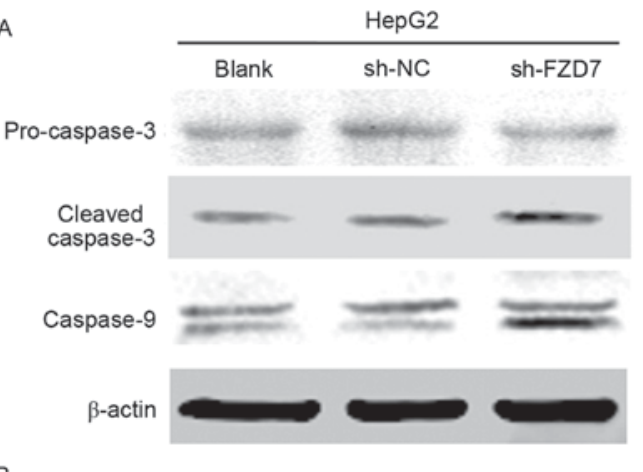

a

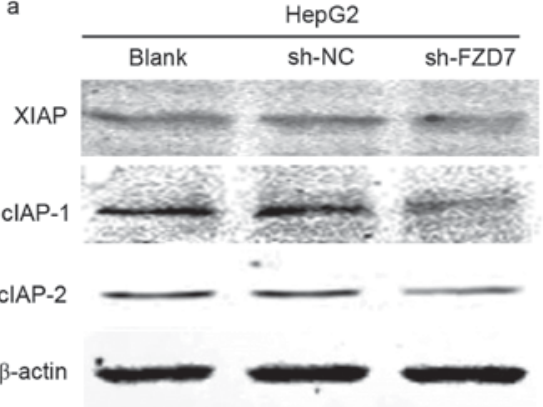

b

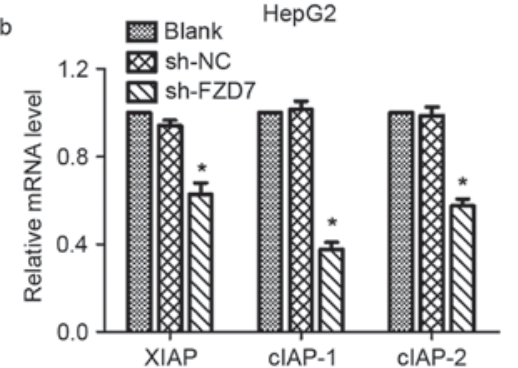

C

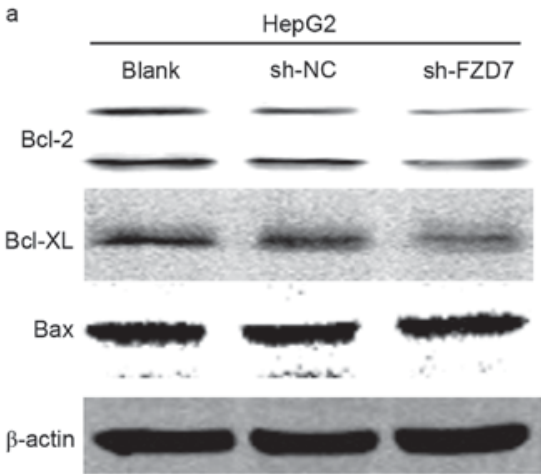

b

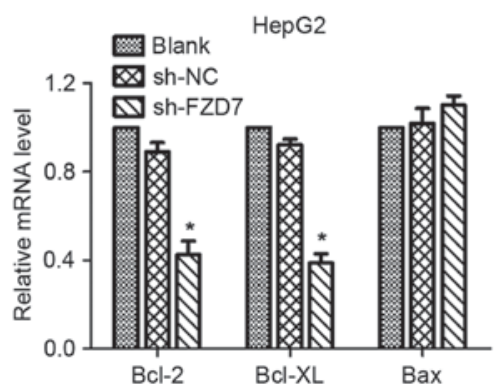

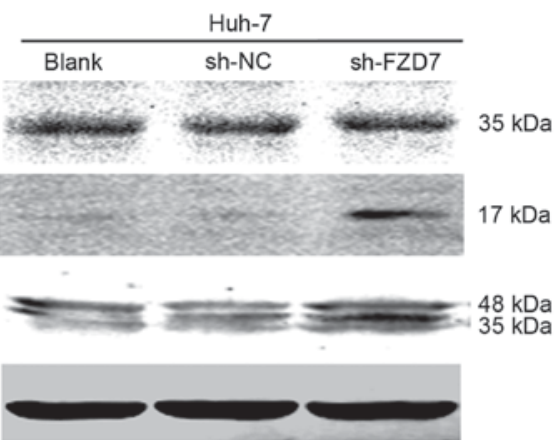
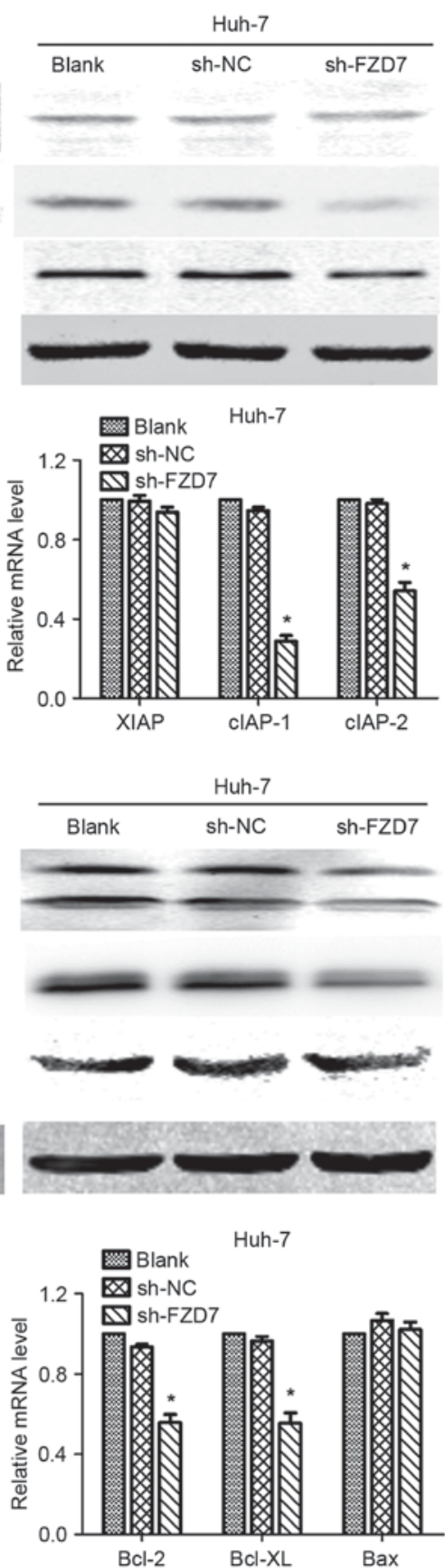

Figure 3. Effects on apoptosis-associated genes expression in sh-FZD7-transfected HepG2 and Huh-7 cells. (A) Activation of caspase-3 and caspase-9 by silencing of FZD7. (B) Effects of knockdown of FZD7 on the levels of the IAP family members: a, protein expression levels of XIAP, cIAP-1 and cIAP-2 were determined by western blot analysis; b, mRNA levels of XIAP, cIAP-1 and cIAP-2 were evaluated by RT-qPCR. (C) Effects of knockdown of FZD7 on the levels of the Bcl-2 family members: a, protein expression levels of Bcl-2, Bcl-XL, Bax were determined by western blot analysis; b, mRNA levels of Bcl-2, Bcl-XL, Bax were evaluated by RT-qPCR. $\beta$-actin was probed as a loading control in western blot analysis; GAPDH was used as the loading control for RT-qPCR. Data are presented as the mean \pm standard deviation of three independent experiments ( $\mathrm{n}=3$; ${ }^{*} \mathrm{P}<0.05$, compared with blank and sh-NC). FZD7, Frizzled-7; sh, short hairpin; NC, negative control; RT-qPCR, reverse transcription-quantitative polymerase chain reaction; XIAP, X-linked inhibitor of apoptosis; cIAP, cellular inhibitor of apoptosis; Bcl-XL, apoptosis regulator Bcl-XL; Bax, BCL2 associated X apoptosis regulator; Bcl-2, apoptosis regulator Bcl-2. 
Consistently, the ELISA results demonstrated that the expression of active P-NF- $\mathrm{kB}$ p65 was significantly repressed in both cell lines compared with the two control groups (Fig. 4B).

Expression of P-Smad2/3 and p53 in both HepG2 and Huh-7 cells. The TGF- $\beta /$ Smad signaling pathway, which serves an important role in the development of liver cancer, crosstalks with NF- $\mathrm{NB}$ p65 and Wnt signaling pathways. Thus, it was hypothesized whether downregulated FZD7 affects the TGF- $\beta /$ Smad signaling pathway. Therefore, the expression levels of $\operatorname{Smad} 2 / 3$ and P-Smad2/3 were examined using western blot analysis. The results revealed that the levels of P-Smad $2 / 3$ were markedly upregulated in both cell lines without alteration to the levels of Smad2/3. In addition, in order to determine other possible mechanisms underlying FZD7 knockdown-induced cell apoptosis, the protein expression of p53 was detected. No marked differences in the expression of p53 were observed among the three groups in both cell lines (Fig. 5).

Association between the TGF- $\beta /$ Smad signaling pathway and $N F-\kappa B$ p 65 in HepG, 2 and Huh-7 cells. In order to investigate the interaction between the TGF- $\beta /$ Smad signaling pathway and NF- $\mathrm{BB}$ p65, the TGF- $\beta /$ Smad signaling pathway was suppressed using shRNA-TGF- $\beta$ RII in both cell lines. Notably, compared with the sh-NC group, no significant differences in the cell apoptosis rate were observed following flow cytometric analysis (Fig. 6A). The expression of nuclear NF- $\mathrm{KB}$ p65 was markedly decreased in HepG2 cells, as determined using western blot analysis (Fig. 6B). In addition, the ELISA revealed no significant differences in P-NF- $\mathrm{kB}$ p65 concentrations amongst the three groups in both cell lines (Fig. 6C).

\section{Discussion}

FZD7, an important receptor of the Wnt signaling pathway, has been demonstrated to be overexpressed in $90 \%$ of HCC cases, most of which are associated with chronic hepatitis B virus infection (19). The Wnt/ $\beta$-catenin signaling pathway is one of the most significant pathways involved in the regulation of cell proliferation, differentiation, migration, apoptosis and survival $(1,2)$. The pharmacological inhibition of FZD7 induces apoptosis of HCC cell lines through the modulation of PKC $\delta$ and $\beta$-catenin (17). However, the other molecular mechanisms underlying the association between FZD7 and apoptosis in HCC cells remain unclear and require elucidation. In the present study, it was demonstrated that the silencing of FZD7 expression inhibited the proliferative ability of HCC cells through the induction of cell apoptosis and the mechanisms underlying the anti-apoptotic effects of FZD7 were further analyzed. The results of the current study revealed that caspases and/or Bcl-2 family members participated in the anti-apoptotic process of FZD7. FZD7-induced NF- $\mathrm{BB}$ transcriptional activity appeared to induce the expression of several Bcl-2 and IAP family members, consequently leading to the suppression of HCC cell apoptosis. In addition, the TGF- $\beta /$ Smad signaling pathway appeared to partially participate in this molecular mechanism.

In adult mammals, apoptosis is essential for normal homeostasis, with billions of cells undergoing the process

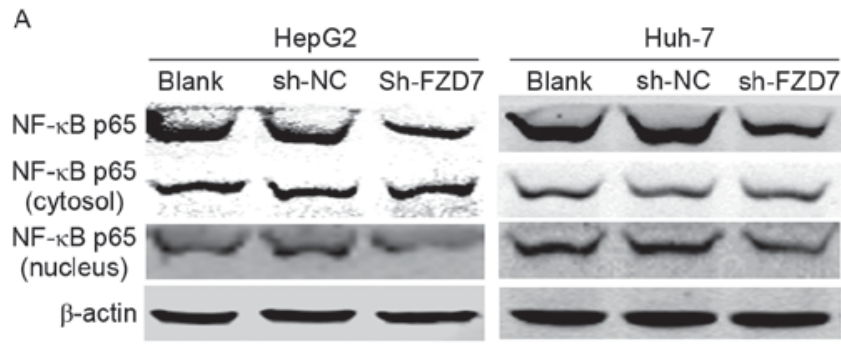

B

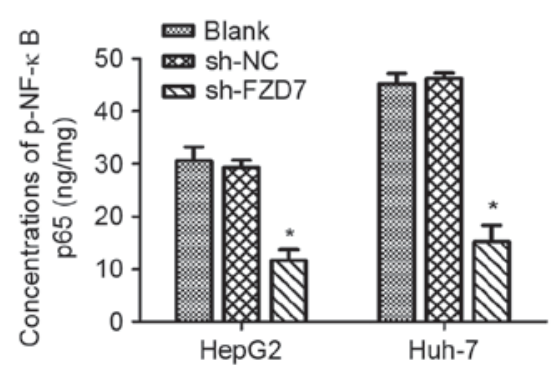

Figure 4. Effects of knockdown of FZD7 on the expression and activities of NF- $\kappa$ B p65 in HepG2, and Huh-7 cells. (A) Total protein, the nuclear protein and the plasma protein expression levels of NF- $\kappa \mathrm{B}$ p 65 were determined by western blot analysis. $\beta$-actin was probed as a loading control. (B) The level of phosphorylated active NF- $\kappa \mathrm{B}$ p 65 of the nuclear protein was evaluated by ELISA. Data are presented as the mean \pm standard deviation of three independent experiments $\left(\mathrm{n}=3 ;{ }^{*} \mathrm{P}<0.05\right.$, compared with blank and sh-NC). FZD7, Frizzled-7; sh, short hairpin; NC, negative control; NF, nuclear factor; p-, phosphorylated.

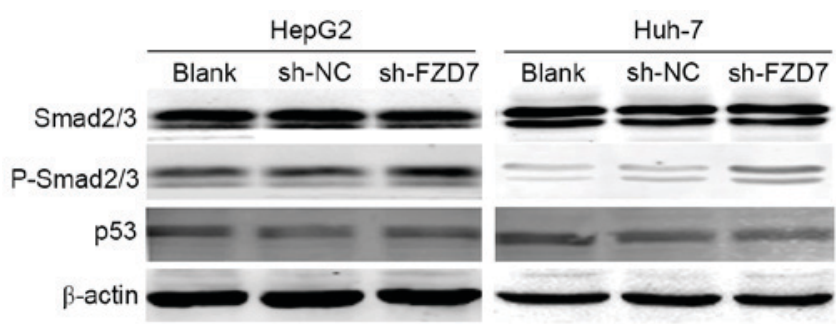

Figure 5. Protein expression levels of Smad2/3, P-Smad2/3 and p53 were determined by western blot analysis in HepG2, and Huh-7 cells. $\beta$-actin was probed as a loading control. p-, phosphorylated; p53, cellular tumor antigen p53; FZD7, Frizzled-7; sh, short hairpin; NC, negative control.

daily to maintain tissue integrity through a balance between cell proliferation and death (20). The proliferation and differentiation of tumor cells are involved in tumor invasion; therefore, inhibition of HCC growth, and promotion of HCC apoptosis are important targets in cancer treatment $(21,22)$. The caspase and Bcl-2 families serve important roles in inducing apoptosis. Caspases are synthesized initially as single polypeptide chains representing the latent precursors that undergo proteolytic processing at specific residues to produce the subunits that form an active heterotetrameric protease (23). According to the functional differences, Bcl-2 family members have been classified as anti-apoptotic or pro-apoptotic; the anti-apoptotic proteins comprise apoptosis regulator Bcl-2, Bcl-XL, Bcl-w and myeloid cell leukemia 1, and the pro-apoptotic proteins include apoptosis regulator Bax, Bcl-2 homologous antagonist/killer, and Bcl2-associated agonist of cell death. Accumulating evidences have revealed 

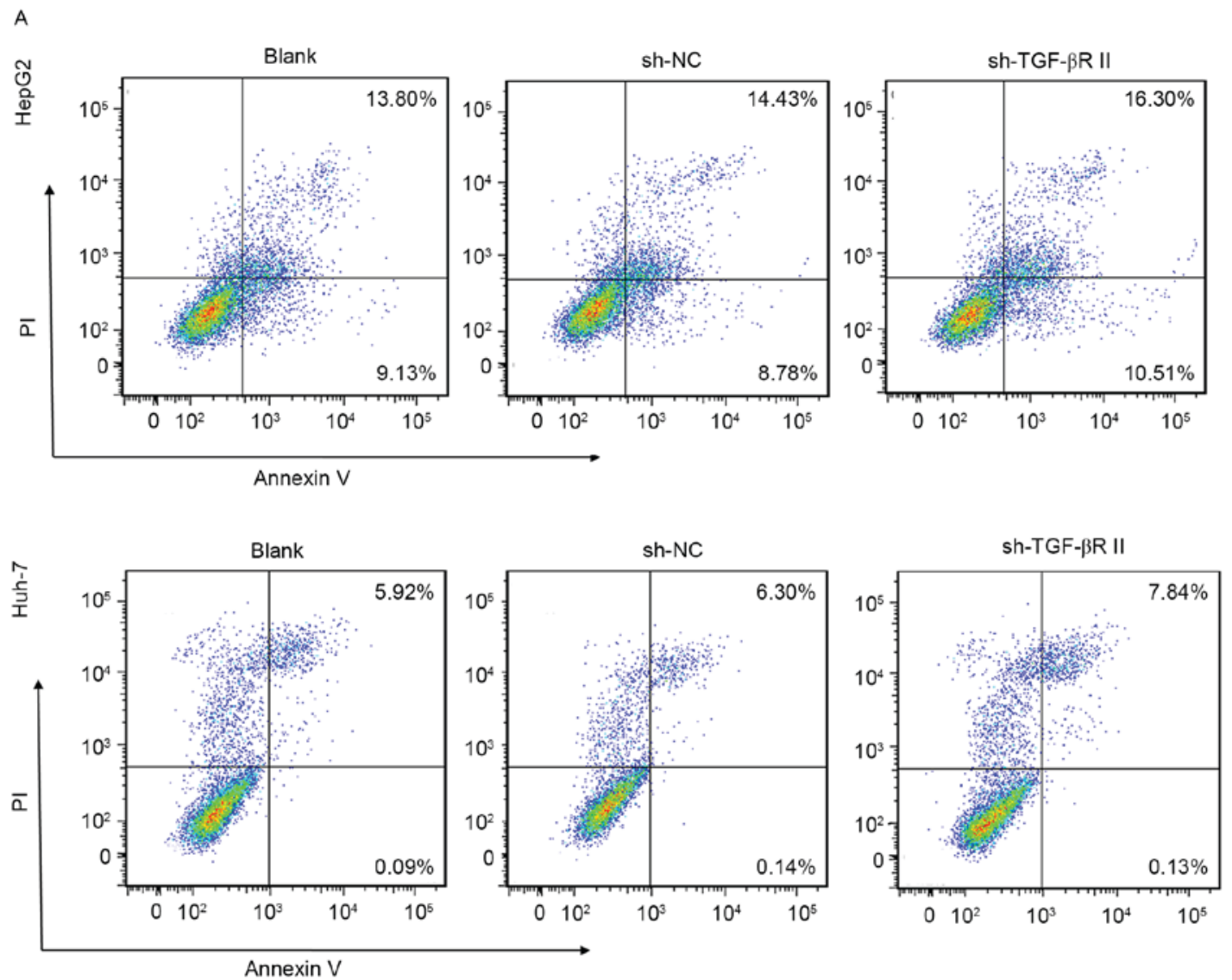

B
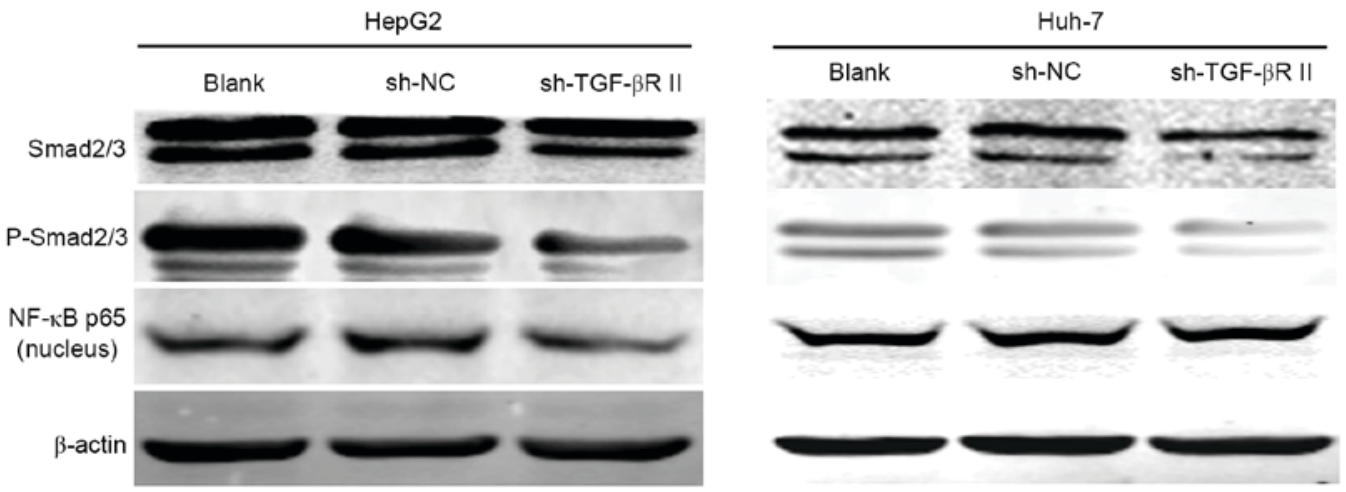

C

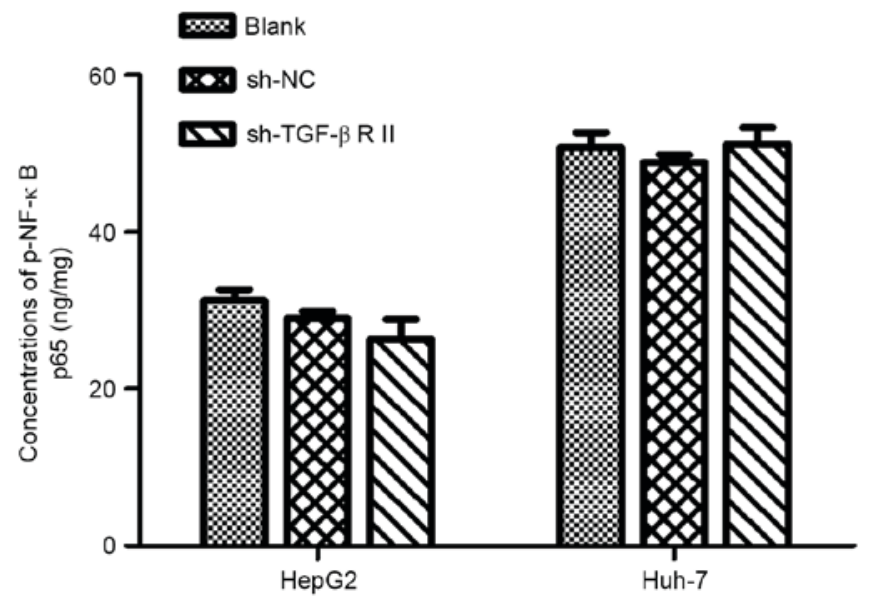

Figure 6. Association between the TGF- $\beta /$ Smad signaling pathway and NF- $\mathrm{KB}$ p65. (A) Effects of TGF- $\beta$ RII knockdown on cell apoptosis rate in HepG2 and Huh-7 cells. (B) Total protein of P-Smad2/3 and the nuclear protein of NF-кB p65 were determined by western blot analysis. $\beta$-actin was probed as a loading control. (C) Level of active p-NF- $\mathrm{kB}$ p 65 of the nuclear protein was evaluated by ELISA. Data are presented as the mean \pm standard deviation of three independent experiments $(\mathrm{n}=3)$. FZD7, Frizzled-7; sh, short hairpin; NC, negative control; TGF- $\beta$ RII, transforming growth factor- $\beta$ receptor II; PI, propidium iodide; NF, nuclear factor; p-, phosphorylated. 
that mitochondria are associated with cell apoptosis (24). The anti-apoptotic Bcl-2 proteins are pro-survival and preserve the integrity of the mitochondrial outer membrane by binding to, and inhibiting pro-apoptotic Bcl-2 proteins (20). Thus, the ratio between the level of $\mathrm{Bcl}-2$ and $\mathrm{Bax}$, decides if a cell reacts to an apoptotic signal. In the present study, silencing of FZD7 markedly increased the activities of caspase-3 and caspase-9, and decreased the Bcl-2/Bax ratio in HepG2 and Huh-7 cells.

Additionally, IAPs, a group of signaling molecules, function in a range of cellular activities, including the inhibition of caspases and the promotion of cell cycle progression (25). Therefore, the downregulation of IAPs relieves the inhibition caused on pro-apoptotic signaling and increases the activation of caspases, thus activating cell death (26). Furthermore, it was demonstrated that patients with HCC exhibit increased expression of cIAP-1, cIAP-2, NAIP, XIAP and Survivin, as compared with the corresponding cirrhotic tissues (27). In the present report, it was revealed that the knockdown of FZD7 promoted apoptosis, and was accompanied by the downregulation of IAP family members in HepG2 and Huh-7 cells.

$\mathrm{NF}-\kappa \mathrm{B}$, a prosurvival transcription factor is identified in various tissues and organs, and can promote tumorigenesis, tumor cell proliferation, invasion and metastasis (28). Several studies have suggested that $\mathrm{NF}-\kappa \mathrm{B}$ exhibits tumor-promoting effects in HCC $(29,30)$. In a $\beta$-catenin-induced HCC model, the activation of $N F-\kappa B$ was identified to be essential for cancer development (31). In addition, $N F-\kappa B$ serves a role in mediating a number of anti-apoptotic factors, including Bcl-2, Bcl-XL, and IAPs (32). These findings support the results of the present study whereby $\beta$-catenin, which was inhibited by the downregulation of FZD7 expression, impaired NF- $\kappa \mathrm{B}$ transcriptional activity. In addition, the induction of apoptosis was accompanied by selective inhibition of Bcl-2 and IAP families, two pro-survival NF- $\kappa \mathrm{B}$ target genes. This suggests that NF- $\mathrm{B}$ P65 serves an essential role in FZD7 knockdown-induced apoptosis.

The TGF- $\beta$ /Smad signaling pathway serves a bidirectional role in cancer progression and crosstalks with the $\mathrm{NF}-\kappa \mathrm{B}$ p65 and Wnt signaling pathways. TGF- $\beta$ usually suppresses $N F-\kappa B$ activity in normal cells, and $N F-\kappa B$ activation induces Smad7 expression, which in turn inhibits TGF- $\beta$ signaling $(33,34)$. Furthermore, TGF- $\beta$ and Wnt $/ \beta$-catenin signaling pathways include common downstream effectors, Smad3, Smad4, and TCF/LEF (35). In proximal tubular epithelial cells, the downregulation of $\beta$-catenin resulted in increased the expression of Smad3 (36). Consistent with previous findings, the present study demonstrated that inhibition of the Wnt/ $\beta$-catenin signaling pathway through FZD7 silencing markedly increased the expression of $\mathrm{P}-\mathrm{Smad} 2 / 3$. P-Smad2/3 is a principal active substance of the TGF- $\beta /$ Smad signaling pathway, thus this result appears to partially account for the observed changes to $N F-\kappa B$ p65 expression. However, when the TGF- $\beta /$ Smad signaling pathway was repressed, the cell apoptosis rate and $\mathrm{NF}-\kappa \mathrm{B}$ expression remained unchanged in HCC cells. This may be due to the complex role of the TGF- $\beta /$ Smad pathway in liver cancer. In spite of this, we speculate whether inhibition of the Wnt/ $\beta$-catenin signaling pathway by knockdown of FZD7 induces the antitumor function of the TGF- $\beta / \mathrm{Smad}$ signaling pathway in HCC cells.
It is well known that the tumor suppressor p53 interacts with Bcl-2 proteins at the mitochondria. Notably, the expression of p53 remained unchanged in sh-FZD7-transfected HCC cells. However, the possibility that FZD7 may regulate the function of p53 cannot be excluded. Further studies using p53 wild-type are warranted to distinguish among these possibilities.

In conclusion, the results of the present study demonstrated that high expression levels of FZD7 inhibited the apoptosis of HCC cells, which appears to account for its tumor-promoting role. These anti-apoptotic mechanisms were mediated through the modulation of $\mathrm{NF}-\kappa \mathrm{B}$, the selective regulation of the Bcl-2 and IAP family, and the inactivation of caspase-3 and caspase-9. The TGF- $\beta$ /Smad signaling pathway serves a valuable role in this molecular mechanism. These results have provided an insight into the possible underlying mechanisms for the association between FZD7 and apoptosis in HCC.

\section{Acknowledgements}

The present study was supported by the Health Department Foundation of Jiangsu province (grant no. H201322).

\section{References}

1. Ochoa-Hernández AB, Juárez-Vázquez CI, Rosales-Reynoso MA and Barros-Nunez P: WNT- $\beta$-catenin signaling pathway and its relationship with cancer. Cir Cir 80: 389-398, 2012 (In Spanish).

2. Liu F and Millar SE: Wnt/beta-catenin signaling in oral tissue development and disease. J Dent Res 89: 318-330, 2010.

3. Lee HS, Park MH, Yang SJ, Park KC, Kim NS, Kim YS, Kim DI, Yoo HS, Choi EJ and Yeom YI: Novel candidate targets of Wnt/beta-catenin signaling in hepatoma cells. Life Sci 80: 690-698, 2007.

4. Ogasawara N, Tsukamoto T, Mizoshita T, Inada K, Cao X, Takenaka Y, Joh T and Tatematsu M: Mutations and nuclear accumulation of beta-catenin correlate with intestinal phenotypic expression in human gastric cancer. Histopathology 49: 612-621, 2006.

5. Ozaki S, Ikeda S, Ishizaki Y, Kurihara T, Tokumoto N, Iseki M, Arihiro K, Kataoka T, Okajima M and Asahara T: Alterations and correlations of the components in the Wnt signaling pathway and its target genes in breast cancer. Oncol Rep 14: 1437-1443, 2005.

6. Martensson A, Oberg A, Jung A, Cederquist K, Stenling R and Palmqvist R: Beta-catenin expression in relation to genetic instability and prognosis in colorectal cancer. Oncol Rep 17: 447-452, 2007.

7. Fuchs SY, Ougolkov AV, Spiegelman VS and Minamoto T: Oncogenic beta-catenin signaling networks in colorectal cancer. Cell Cycle 4: 1522-1539, 2005.

8. Dann CE, Hsieh JC, Rattner A, Sharma D, Nathans J and Leahy DJ: Insights into Wnt binding and signalling from the structures of two Frizzled cysteine-rich domains. Nature 412: 86-90, 2001.

9. Holland JD, Klaus A, Garratt AN and Birchmeier W: Wnt signaling in stem and cancer stem cells. Curr Opin Cell Biol 25: 254-264, 2013.

10. Ye N, Wang B, Quan ZF, Pan HB, Zhang ML and Yan QG: The research progress of the interactions between miRNA and Wnt/beta-catenin signaling pathway in breast cancer of human and mice. Asian Pac J Cancer Prev 15: 1075-1079, 2014.

11. Arend RC, Londoño-Joshi AI, Straughn JM Jr and Buchsbaum DJ: The Wnt/ $\beta$-catenin pathway in ovarian cancer: A review. Gynecol Oncol 131: 772-779, 2013

12. Chen C, Xue Y, Zhang D, Xu W, Xu H, Yao H, Pei D and Gu Y: Short hairpin RNA silencing of TGF- $\beta$ RII and FZD-7 synergistically suppresses proliferation and metastasis of hepatocellular carcinoma cells. Oncol Lett 11: 2039-2046, 2016.

13. Saran U, Arfuso F, Zeps N and Dharmarajan A: Secreted frizzled-related protein 4 expression is positively associated with responsiveness to cisplatin of ovarian cancer cell lines in vitro and with lower tumour grade in mucinous ovarian cancers. BMC Cell Biol 13: 25, 2012 
14. Nojima M, Suzuki H, Toyota M, Watanabe Y, Maruyama R, Sasaki S, Sasaki Y, Mita H, Nishikawa N, Yamaguchi K, et al: Frequent epigenetic inactivation of SFRP genes and constitutive activation of Wnt signaling in gastric cancer. Oncogene 26: 4699-4713, 2007.

15. Suzuki H, Gabrielson E, Chen W, Anbazhagan R, van Engeland M, Weijenberg MP, Herman JG and Baylin SB: A genomic screen for genes upregulated by demethylation and histone deacetylase inhibition in human colorectal cancer. Nat Genet 31: 141-149, 2002.

16. Granados-Principal S, Quiles JL, Ramirez-Tortosa C, Camacho-Corencia P, Sanchez-Rovira P, Vera-Ramirez L and Ramirez-Tortosa MC: Hydroxytyrosol inhibits growth and cell proliferation and promotes high expression of sfrp4 in rat mammary tumours. Mol Nutr Food Res 55 (Suppl 1): S117-S126, 2011.

17. Nambotin SB, Lefrancois L, Sainsily X, Berthillon P, Kim M, Wands JR, Chevallier M, Jalinot P, Scoazec JY, Trepo C, et al: Pharmacological inhibition of Frizzled-7 displays anti-tumor properties in hepatocellular carcinoma. J Hepatol 54: 288-299, 2011.

18. Livak KJ and Schmittgen TD: Analysis of relative gene expression data using real-time quantitative PCR and the 2(-Delta Delta C(T)) method. Methods 25: 402-408, 2001

19. Merle P, de la Monte S, Kim M, Herrmann M, Tanaka S, Von Dem Bussche A, Kew MC, Trepo C and Wands JR: Functional consequences of frizzled-7 receptor overexpression in human hepatocellular carcinoma. Gastroenterology 127: 1110-1122, 2004.

20. Zheng JH, Viacava Follis A, Kriwacki RW and Moldoveanu T: Discoveries and controversies in BCL-2 protein-mediated apoptosis. FEBS J 283: 2690-2700 2016.

21. Merle P and Mornex F: Medical therapies for hepatocellular carcinoma. Cancer Radiother 15: 28-31, 2011 (In French).

22. Kim JK, Kim BH, Baek SM, Shin DH, Kim WJ, Jeon YK, Kim SS and Kim IJ: Incidentally detected inoperable malignant pheochromocytoma with hepatic metastasis treated by transcatheter arterial chemoembolization. Endocrinol Metab (Seoul) 29: 584-589, 2014.

23. Philchenkov A, Zavelevich M, Kroczak TJ and Los M: Caspases and cancer: Mechanisms of inactivation and new treatment modalities. Exp Oncol 26: 82-97, 2004.

24. Pellecchia M and Reed JC: Inhibition of anti-apoptotic Bcl-2 family proteins by natural polyphenols: New avenues for cancer chemoprevention and chemotherapy. Curr Pharm Des 10: 1387-1398, 2004.

25. Wang K and Lin B: Inhibitor of apoptosis proteins (IAPs) as regulatory factors of hepatic apoptosis. Cell Signal 25: 1970-1980, 2013.
26. Hengartner MO: The biochemistry of apoptosis. Nature 407: 770-776, 2000

27. Zender L, Spector MS, Xue W, Flemming P, Cordon-Cardo C, Silke J,Fan ST, Luk JM, Wigler M, Hannon GJ, et al: Identification and validation of oncogenes in liver cancer using an integrative oncogenomic approach. Cell 125: 1253-1267, 2006.

28. Chaturvedi MM, Sung B, Yadav VR, Kannappan R and Aggarwal BB: NF- $\kappa$ B addiction and its role in cancer: 'One size does not fit all'. Oncogene 30: 1615-1630, 2011.

29. Pikarsky E, Porat RM, Stein I, Abramovitch R, Amit S, Kasem S, Gutkovich-Pyest E, Urieli-Shoval S, Galun E and Ben-Neriah Y: NF-kappaB functions as a tumour promoter in inflammation-associated cancer. Nature 431: 461-466, 2004

30. Haybaeck J,Zeller N, Wolf MJ, Weber A, Wagner U, Kurrer MO, Bremer J, Iezzi G, Graf R, Clavien PA, et al: A lymphotoxin-driven pathway to hepatocellular carcinoma. Cancer Cell 16: 295-308, 2009.

31. Anson M, Crain-Denoyelle AM, Baud V, Chereau F, Gougelet A, Terris B, Yamagoe S, Colnot S, Viguier M, Perret C and Couty JP: Oncogenic $\beta$-catenin triggers an inflammatory response that determines the aggressiveness of hepatocellular carcinoma in mice. J Clin Invest 122: 586-599, 2012.

32. Schattenberg JM, Schuchmann M and Galle PR: Cell death and hepatocarcinogenesis: Dysregulation of apoptosis signaling pathways. J Gastroenterol Hepatol 26 (Suppl 1): S213-S219, 2011.

33. Hong S, Lim S, Li AG, Lee C, Lee YS, Lee EK, Park SH, Wang XJ and Kim SJ: Smad7 binds to the adaptors TAB2 and TAB 3 to block recruitment of the kinase TAK1 to the adaptor TRAF2. Nat Immunol 8: 504-513, 2007.

34. Lee YS, Kim JH, Kim ST, Kwon JY, Hong S, Kim SJ and Park SH: Smad7 and Smad6 bind to discrete regions of Pellino-1 via their MH2 domains to mediate TGF-beta1-induced negative regulation of IL-1R/TLR signaling. Biochem Biophys Res Commun 393: 836-843, 2010

35. Nishita M, Hashimoto MK, Ogata S, Laurent MN, Ueno N, Shibuya $\mathrm{H}$ and Cho KW: Interaction between Wnt and TGF-beta signalling pathways during formation of Spemann's organizer. Nature 403: 781-785, 2000.

36. Zhang M, Lee CH, Luo DD, Krupa A, Fraser D and Phillips A: Polarity of response to transforming growth factor-betal in proximal tubular epithelial cells is regulated by beta-catenin. J Biol Chem 282: 28639-28647, 2007.

c) (i) $\odot$ This work is licensed under a Creative Commons (c) $\mathrm{EY}$ NO ND Attribution-NonCommercial-NoDerivatives 4.0 International (CC BY-NC-ND 4.0) License. 